\section{¿De quién es la diplomacia pública? El rol del Departamento Autónomo de Prensa y Publicidad (DAPP) en la propaganda exterior cardenista}

Where does public diplomacy belongs? The role of the
Departamento Autónomo de Prensa y Publicidad (DAPP)
on Mexico's foreign propaganda during cardenismo

Universidad del Desarrollo, Santiago de Chile, Chile

Correo electrónico: sdummer@plagio.cl

(1979) Doctora en Historia de América Latina por la Universidad Libre de Berlín, Magíster y Licenciada en Historia por la Pontificia Universidad Católica de Chile. Autora del libro Sin tropicalismos ni exageraciones. La construcción de la imagen de Chile para la Exposición Iberoamericana de Sevilla en 1929 (RIL, 2012). Profesora de Historia y Teoría del Diseño en la Universidad del Desarrollo, y de la Cátedra México en la Universidad Católica de Chile.

Resumen

El artículo explora el rol que tuvo el Departamento Autónomo de Prensa y Publicidad (1937-1939) sobre la diplomacia pública de México. Su creación interrumpió la labor que realizaba tradicionalmente la Secretaría de Relaciones Exteriores, obligando a redefinir qué organismo era responsable de la propaganda exterior de la nación: ¿aquél que se encargaba de las comunicaciones del gobierno, o la dependencia responsable de las relacionas internacionales del país? Se profundiza en el desafío que representó para el DAPP considerar la mediación cultural que requiere la diplomacia pública, y en los esfuerzos de la SRE por mantener cierto control sobre dicha labor.

Palabras claves

Departamento Autónomo de Prensa y Publicidad (DAPP), Diplomacia Pública, Propaganda, Mediación Cultural, Lázaro Cárdenas, Secretaría de Relaciones Exteriores

The article explores the role of the Autonomous Department of Press and Publicity (DAPP) on Mexico's Diplomacy in 1937-1939. Created by Lázaro Cárdenas to unify the state propaganda under a centralized agency, the DAPP came to disturb the long-lasting practice that international public diplomacy was carried out exclusively by the Ministry of Foreign Affairs (SRE). The analysis focuses on the question of which organization should perform the external propaganda, the DAPP's challenge to consider the cultural mediation that public diplomacy requires, and the SRE'S efforts to maintain some control over that work.

Keywords
Autonomous Department of Press and Publicity (DAPP), Public Diplomacy, Propaganda, Cultural Mediation, Lázaro Cárdenas, Ministry of Foreign Affairs
Recibido/Received

Aprobado/Approved
27 de julio de 2017

2 de febrero de 2018
ESTUDIOS DE HISTORIA MODERNA Y CONTEMPORÁNEA DE MÉXICO 55, ENERO-JUNIO 2018, 279-312 DOI: http://dx.doi.org/10.22201/iih.24485004e.2018.55.63301 


\title{
¿De quién es la diplomacia pública? El rol del Departamento Autónomo de Prensa y Publicidad (DAPP) en la propaganda exterior cardenista
}

\author{
Sylvia Dümmer Scheel
}

Los gobiernos posrevolucionarios mexicanos implementaron, desde temprano, importantes esfuerzos de diplomacia pública, ${ }^{1}$ a fin de ganar las simpatías de la opinión pública internacional hacia sus causas y revertir la antipropaganda impulsada por sus adversarios en el extranjero. ${ }^{2}$ Tales campañas fueron dirigidas desde sus inicios por la Secretaría de Relaciones Exteriores (SRE), organismo sobre el que, por ley, recaía la responsabilidad de velar por el prestigio internacional del país. Así, durante la década de 1920 y hasta bien entrados los años 30, la Oficina de Publicidad de la SRE implementó diversas campañas de propaganda en colaboración con los embajadores y cónsules de México en el exterior. ${ }^{3}$ Sin embargo, dicha continuidad fue interrumpida en 1937 con la creación del Departamento Autónomo de Prensa y Publicidad (DAPP), un experimento inédito en el país que centralizaba bajo un solo organismo todas las labores de propaganda del gobierno, incluida aquella dirigida hacia el extranjero. Con ello, el presidente Cárdenas ponía fin al monopolio de la SRE sobre la propaganda exterior y la organizaba según un modelo nuevo, con la esperanza de hacer frente

${ }^{1}$ En este artículo se utilizará diplomacia pública como sinónimo de propaganda exterior, considerando que, aunque el término comenzó a utilizarse en la segunda mitad del siglo xx para tomar distancia de los prejuicios hacia el vocablo propaganda, se refiere a las mismas prácticas que se ejercían con anterioridad.

2 Sobre la diplomacia pública de las facciones revolucionarias y los gobiernos posrevolucionarios anteriores a Cárdenas, véase Cronlund Anderson (2000); Smith (1995); Yankelevich (1995, 1997, 1999); Strauss Neuman (1983); Macías Richard (1991); Britton (1988).

3 La Oficina de Publicidad de la Secretaría de Relaciones Exteriores fue fundada en 1922, durante la administración de Álvaro Obregón.

ESTUDIOS DE HISTORIA MODERNA Y CONTEMPORÁNEA DE MÉXICO 55, enero-junio 2018, 279-312

DOI: http://dx.doi.org/10.22201/iih.24485004e.2018.55.63301 
de mejor forma a los virulentos ataques que tanto sus enemigos internos como grupos de interés norteamericanos realizaban contra su gobierno en la prensa foránea.

El DAPP, por largo tiempo ignorado por la historiografía, ha comenzado a ser tomado en cuenta en los últimos años en relación a varias de sus aristas. ${ }^{4}$ Sin embargo, poco se ha escrito aún sobre su rol en la propaganda exterior del país, pese a que su existencia coincidió con la más agresiva guerra de propaganda del México posrevolucionario, como fue la surgida con Estados Unidos luego de la expropiación petrolera de $1938 .^{5} \mathrm{El}$ rol del DAPP en la propaganda exterior resulta relevante no sólo porque permite conocer mejor el funcionamiento de dicha oficina, sino porque problematiza la naturaleza de la diplomacia pública misma. En este sentido, la creación del departamento lanzó sobre la propaganda exterior de México una pregunta que bien podía trascender a este país o a este período particular: ¿Sobre cuál organismo del Estado debía recaer la diplomacia pública? ¿Sobre aquél que ejercía las labores de información y propaganda oficial, o sobre el que se encargaba de las relaciones internacionales del país? El presente artículo aborda la creación y el funcionamiento del DAPP a la luz de esta pregunta, profundizando en sus aportes y limitaciones sobre la diplomacia pública de México y en los esfuerzos de la Secretaría de Relaciones Exteriores por mantener cierto control sobre la misma. En ese sentido, se problematiza especialmente el desafío que representó para ambos organismos la necesidad de incorporar la mediación cultural en las campañas internacionales, así como el imperativo de guiarse por los requerimientos de política exterior.

${ }^{4}$ Aunque el DAPP suele ser mencionado en estudios sobre el período cardenista o sobre comunicación en México, hasta hace poco, las únicas publicaciones que existían específicamente sobre el tema eran la tesis de López González (2002) y el artículo de Mejía Barquera (2010). Ambos se centran especialmente en resumir las Memorias de labores del DAPP y son sumamente descriptivos. En los últimos años ha surgido un nuevo interés por el DAPP, que ha sido estudiado a partir de su producción cinematográfica (Ruiz Ojeda, 2012; Vázquez Mantecón, 2013); su propaganda radial y en medios impresos (Pilatowsky Goñi, 2014); su aporte visual y artístico (Cruz Porchini, 2014) o su rol en la propaganda dirigida al interior del país (González Salinas, 2016).

${ }^{5}$ El estudio de Cruz Porchini (2014) es el único que se sitúa en el plano internacional al mencionar la labor del DAPP en gestiones de diplomacia cultural, aunque se circunscribe estrictamente al plano artístico. 


\section{El Departamento Autónomo de Prensa y Publicidad (1937-1939): centralización y profesionalización de la publicidad gubernamental}

El Departamento Autónomo de Prensa y Publicidad (DAPP) fue fundado por Lázaro Cárdenas en el contexto de un creciente auge internacional de la propaganda como disciplina, profesión y herramienta política. ${ }^{6}$ La creación de un Ministerio de Propaganda por parte de la Alemania nazi fue el ejemplo más evidente del protagonismo que había cobrado esta herramienta en la década de 1930, aunque no se trató del único caso, ya que también se abrieron oficinas similares en otros países. El DAPP fue, de este modo, signo de los tiempos que se vivían. No obstante, su creación respondió a su vez a los procesos políticos particulares que estaban ocurriendo dentro de México. La administración de Cárdenas -considerado el más radical de los gobiernos posrevolucionarios-, asumió el poder con un importante programa reformista por delante, que contemplaba desde repartición de tierras a cambios drásticos en el sistema educativo.7 Según diagnosticaba el propio Cárdenas, su Plan Sexenal solo podría llevarse a cabo de forma exitosa si se fortalecían los mecanismos de propaganda estatal, a través de los cuales habría que lograr generar comprensión y aceptación hacia el proceso de transformación que vendría. Esto, tanto entre la población mexicana, recelosa del nuevo rol que adquiriría el Estado, como entre el público exterior, temeroso del radicalismo mexicano y desinformado por las campañas de desprestigio orquestadas por sus adversarios extranjeros. Entre los mexicanos se buscaba, además, ejercer una educación ideológica según los principios de la nueva administración, a fin de que se comprometieran

${ }^{6}$ Los textos y estudios sobre propaganda que se comenzaron a publicar con fuerza en Estados Unidos y Alemania en la década de 1920 alcanzaron un verdadero peak cuantitativo en la década siguiente, al tiempo que se multiplicaban los profesionales dedicados al tema. Por su parte, tras el éxito obtenido a través del uso de propaganda durante la primera Guerra Mundial, muchos gobiernos comenzaron a considerar la conveniencia de utilizarla también en tiempos de paz. Sobre historia de la propaganda en la primera mitad del siglo xx, véase Bussemer (2005, p. 64-93); Sproule (2005).

7 Sobre el gobierno de Lázaro Cárdenas, véase, entre otros, Medin (1975); Semo (1993); Gilly (1994). 
activamente con ella. ${ }^{8}$ Bajo todos estos argumentos, la creación de un organismo gubernamental encargado de realizar propaganda fue explicada por las autoridades como un derivado forzoso de la adopción del Plan Sexenal y de la transformación política existente. ${ }^{9}$ En ese sentido, Cárdenas concluía en su mensaje al Congreso justificando la fundación del DAPP:

Todo gobierno que no se limite a cuidar el orden, sino que además ejerza funciones definidas que tiendan a fomentar la potencialidad económica del país, así como a fijar conceptos de ética colectiva, debe disponer de un mecanismo adecuado para actuar sobre la atención pública nacional y extranjera. ${ }^{10}$

Aquello no significaba que no existiera propaganda estatal antes del DAPP. Durante los primeros dos años del sexenio cardenista, y tal como había funcionado bajo los gobiernos anteriores, las labores de información y propaganda se encontraban distribuidas entre diversas dependencias del Ejecutivo. Muchas Secretarías contaban con sus propias oficinas de publicidad, a través de las cuales promovían los temas que eran de su particular incumbencia. ${ }^{11}$ Sin embargo, una vez consolidado en el poder, Cárdenas diagnosticó que este modelo atomizado de propaganda no estaba dando los resultados esperados y debía ser modificado. A su parecer, la propaganda gubernamental se había desarrollado hasta el momento de manera inconsecuente y sin obedecer a un propósito general del Estado por el hecho de carecer de una organización determinada. ${ }^{12}$ Otros encargados gubernamentales también advertían acerca de la desorganizada labor publicitaria que desarrollaban las dependencias del Ejecutivo y la anarquía de declaraciones que existía entre los empleados públicos, siendo el

${ }^{8}$ De Lázaro Cárdenas del Río (en adelante LCR) a Secretarios del Congreso de la Unión (en adelante SCU), 22.12.1936 y 25.12.1936, AGN P LCR 545.2/33; Mary Saint Albans, "Arroyo Ch. and his DAPP”, Modern Mexico, 21.9.1937, 5-7, 24-25.

9 José Rivera P. C., "Las funciones del Departamento Autónomo de Publicidad y Propaganda”, conferencia sustentada el 5 de junio de 1937 en el Palacio de Bellas Artes, publicada en Revista Universidad, n. 17, junio 1937, 13-16.

${ }^{10}$ De LCR a SCU, 25.12.1936, AGN P LCR 545.2/33.

${ }^{11}$ Mijares Palencia (1936, p. 35-37, 84-86).

${ }^{12}$ De LCR a SCU, 25.12.1936, AGN P LCR 545.2/33. 
mayor problema la falta de unidad ideológica entre los diversos órganos de propaganda del Estado. Ello desorientaba a la opinión pública y no ayudaba a unificar a la colectividad en torno al proyecto gubernamental. ${ }^{13}$

Para revertir todas estas falencias, a dos años de iniciado su mandato Cárdenas dio vida al Departamento Autónomo de Publicidad y Propaganda, el cual pocos meses después sería rebautizado como de Prensa y Publicidad. ${ }^{14}$ El organismo comenzó a funcionar el 1 de enero de 1937 buscando aportar a la propaganda gubernamental con dos rasgos esenciales, como fueron la centralización y la profesionalización de dicha labor. El primer aspecto resultaba totalmente inédito en la organización de las comunicaciones del gobierno mexicano: el departamento reunió en un sólo organismo todas las labores de propaganda oficial que hasta el momento habían estado repartidas entre distintas dependencias del Ejecutivo. Las Secretarías perdieron sus atribuciones en este ámbito, siendo sus asignaciones presupuestales para fines de publicidad adjudicadas ahora al presupuesto del DAPP. ${ }^{15}$ Con la centralización de las labores de propaganda se buscaba lograr un aprovechamiento más eficiente de los recursos, pero por sobre todo uniformar las formas y el contenido de la propaganda bajo un solo criterio y evitar así la disparidad ideológica en las declaraciones y publicaciones oficiales. Por eso, el DAPP tendría un control absoluto sobre la labor comunicacional de todas las dependencias oficiales que por cualquier medio contribuyeran a la difusión de ideas. ${ }^{16} \mathrm{El}$ departamento fue dotado además de mayor poder e independencia al definirlo como un organismo autónomo que no

13 "Proyecto de Organización del Departamento Autónomo de Propaganda y Publicidad", 29.12.1936, APIP, carpeta 16, 90/158m, cartón 1; “El Nombre: DAP. El Hombre: Arroyo Ch.”, Hoy, n. 5, 27 de marzo de 1937, 19, 63; Estela Sangines Villalva, "Publicidad sobre Economía”, sin fecha, APIP, carpeta 16, 90/158m, cartón 1; Juan López Alcarer, “Publicidad de Economía”, 27.1.1937, APIP, carpeta 17, 90/158m, cartón 1.

${ }_{14}$ Diario Oficial de la Federación, 30.6.1937, 4; De José Rivera P. C. a Director General de Correos y Telégrafos, 28.9.1937, AGN DGI, caja 7, 101.1/1.

15 “Proyecto de Organización del Departamento Autónomo de Propaganda y Publicidad”, 29.12.1936, APIP, carpeta 16, 90/158m, cartón 1.

${ }^{16}$ Agustín Arroyo Ch. (en adelante AACh), Discurso en el acto inaugural de la radiodifusora X. E. D. P., 15.3.37, FAACh., Archivador “1937”, gaveta 9; Estela Sangines Villalva, “Publicidad sobre Economía”, sin fecha, APIP, carpeta 16, 90/158m, cartón 1; Juan López Alcarer, “Publicidad de Economía”, 27.1.1937, APIP, carpeta 17, 90/158m, cartón 1; Celia Panama D., "Proyecto para el programa de trabajos de la sección educativa”, 15.1.1937, APIP, carpeta 16, 90/158m, cartón 1;

ESTUDIOS DE HISTORIA MODERNA Y CONTEMPORÁNEA DE MÉXICO 55, enero-junio 2018, 279-312 DOI: http://dx.doi.org/10.22201/iih.24485004e.2018.55.63301 
dependía de ninguna Secretaría. ${ }^{17}$ Su director hasta el cierre del departamento en 1939, el político y periodista Agustín Arroyo Ch., debió responder directamente al presidente Cárdenas. ${ }^{18}$

Esta estructuración centralizada tenía una clara inspiración en los modelos de propaganda estatal que diversos gobiernos estaban implementando en Europa, siendo el más emblemático el Ministerio de Propaganda de la Alemania nazi. ${ }^{19}$ Aunque el gobierno mexicano no pretendió controlar todos los aspectos de la vida nacional como hizo el ministerio de Goebbels, sí lo consideró un referente en términos de organización y recabó información sobre su funcionamiento. ${ }^{20}$ Ello, porque como reconocía un periodista a Agustín Arroyo, "los fascistas y nazis desgraciadamente han sentado un precedente en el mundo, [sobre] en qué forma debe hacerse la propaganda". ${ }^{21}$ No obstante, el DAPP no fue una réplica del ministerio nazi, siendo mucho más modesto en su organización, recursos y alcances, y aplicando metodologías bastante distintas de propaganda.

“El Nombre: DAP. El Hombre: Arroyo Ch.”, Hoy, n. 5, 27 de marzo de 1937, 19, 63; Mary Saint Albans, “Arroyo Ch. and his DAPP", Modern Mexico, 21.9.1937, 5-7, 24-25.

${ }^{17}$ Medio año antes de crear el DAPP, en agosto de 1936, Cárdenas había decretado la creación de una Dirección de Publicidad y Propaganda (DPP) perteneciente a la Secretaría de Gobernación, cuyas responsabilidades eran muy similares a las que serían encomendadas luego al departamento autónomo. Sin embargo, la DPP no alcanzó a iniciar sus labores, ya que para Cárdenas quedó pronto demostrado que el organismo encargado requería plena autonomía para desarrollar su labor de manera más eficaz, siendo sus estatutos reformulados para dar forma a lo que sería el DAPP. Diario Oficial de la Federación de los Estados Unidos Mexicanos, 17.8.1936, 1-2; Dirección General de Egresos, Secretaría de Hacienda y Crédito Público, informe “Departamento de publicidad”, sin fecha, AGN P LCR 545.2/33; De Luis I. Rodríguez a Ricardo G. Hill, Cónsul Los Ángeles, 9.7.1936, AGN P LCR 544.61/22; De LCR a SCU, 25.12.1936, AGN LCR $545.2 / 33$.

${ }^{18}$ Agustín Arroyo Ch. (1892-1969) había sido gobernador de Guanajuato y, hasta antes de ser nombrado como jefe del DAPP, se desempeñaba como subsecretario de Gobernación del gobierno de Cárdenas. Además de luchador revolucionario y político, Arroyo era periodista, escritor y poeta (décadas más tarde sería director de El Nacional).

${ }^{19}$ Joseph Goebbels, el ministro a cargo, partía del principio de que toda la propaganda del gobierno -incluyendo lo relativo a prensa y cultura- debía ser planificada e implementada por una sola autoridad (él), que respondería directamente a Hitler (Doob, 1950, p. 423, 424).

${ }^{20}$ De Alfonso Guerra, Cónsul General de México en Alemania a AACh., 22.2.37, FAACh., gaveta 9, archivador “1937”; De AACh. a Georg Ahrens, Consejero de la Legación de Alemania en México, 20.1.1937, FAACh., gaveta 3, carpeta "de A/301(D-3)/-1 al..."; “Ministerio del Reich para esclarecimiento popular y propaganda, Berlín”, AGN P LCR 545.2/33.

${ }^{21}$ De R. A. Maier a AACh, 30.3.1938, FAACh, archivador “abril-mayo 1938”, gaveta 8. 
Con la organización de Goebbels tuvo en común, más bien, la idea de una oficina centralizada de propaganda estatal, subordinada directamente al presidente, que funcionara en tiempos de paz y ejerciera abiertamente dicha labor.

El intento por profesionalizar la propaganda estatal, en tanto, también estuvo inspirado en los avances que la disciplina estaba alcanzando a nivel internacional. La elite cardenista aspiraba a profesionalizarse y modernizarse, reuniendo en su programa las innovaciones técnicas, políticas e ideológicas de su época, ${ }^{22}$ búsqueda que se aplicó también a este campo particular. Según palabras del propio Cárdenas, México necesitaba "una publicidad y una propaganda certeras, enérgicas, científicamente preparadas". ${ }^{23}$ El DAPP, por tanto, contaría con un personal eficiente y profesional, aplicaría sistemas de publicidad modernos que tuvieran sustentos metodológicos, e implementaría la infraestructura y tecnología necesaria para potenciar el uso del cine y la radio en la propaganda. ${ }^{24}$

El DAPP resultó ser así un ambicioso proyecto que alteraba en forma radical la organización previa de la propaganda gubernamental mexicana, y que buscaba potenciar los mecanismos de comunicación y persuasión del gobierno poniéndolos a la altura de los más modernos modelos internacionales. Sin embargo, este modelo organizacional aparentemente superior fue siendo desafiado por diversos factores a lo largo de su implementación, los cuales confluyeron para que el departamento fuera eliminado tres años después. Uno de estos cuestionamientos provino, precisamente, desde la propaganda exterior.

\section{¿De quién es la diplomacia pública? La pugna entre el DAPP y la Secretaría de Relaciones Exteriores}

En continuidad con la labor de diplomacia pública que venía desarrollando desde al menos 1922, durante los dos primeros años del sexenio cardenista fue la Secretaría de Relaciones Exteriores la que se encargó de explicar el Plan

\footnotetext{
22 Semo (1993, p. 199-201).

${ }^{23}$ De LCR a SCU, 25.12.1936, AGN LCR 545.2/33.

24 "Proyecto de Organización del Departamento Autónomo de Propaganda y Publicidad", 29.12.1936, APIP, carpeta 16, 90/158m, cartón 1.
} 
Sexenal a la opinión pública extranjera y defender al gobierno de los ataques de propaganda foránea. Durante este período le tocó hacer frente, entre otras polémicas, a las reiteradas acusaciones de comunismo difundidas por la prensa de Estados Unidos y a la antipropaganda impulsada por el clericalismo norteamericano a raíz de las persecuciones religiosas y la educación socialista en México. ${ }^{25}$ Además de continuar con las técnicas tradicionales de diplomacia pública utilizadas por sus antecesores, como era la distribución de publicaciones y la realización de conferencias en el exterior, impulsó nuevos mecanismos de difusión para potenciar su labor. Al poco tiempo de asumir la administración cardenista, la Secretaría inauguró la estación radiofónica X. E. C. R. y comenzó a editar un boletín con columnas sobre la labor constructiva del gobierno titulado Noticiero Semanal (en inglés, Mexican News Sheet), que se enviaba a la prensa extranjera.

No obstante, aunque Cárdenas reconocía los esfuerzos de la SRE en materia de propaganda, durante el segundo año de su mandato comenzó a considerar que sus gestiones no estaban resultando efectivas por realizarse, al igual que el resto de la publicidad oficial, de manera aislada y dispersa. Preocupado por las campañas mediáticas en su contra, el General diagnosticó que la labor de proporcionar información sobre México al extranjero y de rectificar las noticias falsas que allí circulaban debía ser aún más sólida y sistemática. Debía, además, provenir de una organización que mereciera la confianza de los periódicos y agencias informativas de otros países. ${ }^{26}$ Es muy probable que también juzgara necesario organizar un mecanismo para ejercer mayor control sobre la información oficial que circulara fuera de las fronteras, ya que durante el primer año de su gobierno ocurrió que altos funcionarios de su administración realizaron declaraciones contrarias al discurso gubernamental ante periodistas foráneos, las cuales resultaron sumamente contraproducentes y debieron ser desmentidas a través de diversos medios. ${ }^{27}$

${ }^{25}$ Sobre las campañas de propaganda contra México realizadas en Estados Unidos durante el cardenismo, véase Dümmer Scheel (2015).

${ }^{26}$ De LCR a SCU, 25.12.1936, AGN P LCR 545.2/33.

27 De Ángel Rosas, 21.5.1935, AGN P LCR 533.31/1. 
Las críticas hacia el desempeño de la SRE en el plano de la propaganda también provinieron de algunos cónsules. Según éstas, los representantes de México en el exterior carecían de un plan central y de instrucciones claras por parte de la SRE según las cuales orientar su labor, por lo que debían trabajar por iniciativa propia y en forma muy autónoma. Dado que el objetivo del DAPP era precisamente centralizar todo tipo de propaganda, podía haber esperanzas de que esta falencia fuera revertida bajo su dirección. De hecho, su Oficina Técnica elaboró un informe titulado Plan y Sistema General de Propaganda donde se planteó la necesidad de coordinar y encuadrar todas las actividades de difusión, nacional y extranjera, dentro de un mismo programa. ${ }^{28}$

De este modo, al crearse el DAPP quedó contemplado que también la propaganda exterior pasaría a ser dirigida por el nuevo departamento, a fin de revertir estas falencias y hacer más eficientes los procedimientos. El DAPP incorporó bajo sus funciones la labor realizada hasta la fecha por la Secretaría de Relaciones Exteriores, además de la propaganda turística que venía desarrollando el Departamento de Turismo de la Secretaría de Gobernación. ${ }^{29}$ Aquello trajo importantes cambios al interior de la SRE. Aunque la realización de charlas y la distribución del material de propaganda continuó estando a cargo de su servicio exterior, representado por cónsules y embajadores, sí mermó las atribuciones de la SRE en temas de propaganda y trajo cambios en su estructura organizacional. Su Departamento de Publicidad y su imprenta fueron suprimidos y se creó en su reemplazo la Oficina de Coordinación, Biblioteca y Archivo, cuyo rol sería hacer de enlace entre la SRE y el DAPP. La oficina, que contaba con solo cinco empleados, tuvo un papel menor circunscrito prácticamente a tareas de distribución..$^{30}$ De este modo, ante la pregunta de quién debía hacerse cargo de la propaganda exterior del país, el intento de profesionalización de Cárdenas optó por otorgarle dichas funciones al mismo organismo que se haría cargo de la publicidad interior, priorizando así el modelo centralizador.

${ }^{28}$ Rafael Llamosa, Plan y Sistema General de Propaganda, sin fecha, APIP, Carpeta 14, 90/158m, cartón 1. También José Rivera P. C., en su estudio Publicidad Turística de México editado por el DAPP, profundizaba en las distintas instancias de planificación de la propaganda.

29 DAPP, Memoria (1938, p. 114). El Departamento de Turismo de la Secretaría de Gobernación siguió existiendo, pero sin hacerse cargo de labores de publicidad.

30 SRE, Memoria (1941, p. 543). 
Sin embargo, la SRE no aceptó tan fácilmente la pérdida de sus antiguas atribuciones en este ámbito, lo que dio origen a una verdadera pugna burocrática entre ella y el DAPP. Apelando a la expertise de su cartera en cuanto a diplomacia pública, el secretario de Relaciones Exteriores, Eduardo Hay realizó presiones para que la nueva distribución de labores fuera reconsiderada. Sus argumentos se orientaron a los desafíos específicos que representaba la diplomacia pública y a los conocimientos que sobre ella tenía su Secretaría, poniendo en duda la capacidad del DAPP al respecto. En este sentido, advirtió a Agustín Arroyo Ch.:

Hay propaganda que no se puede hacer indistintamente ni en cualquier tiempo a todos los países, pues por circunstancias especiales muchas veces podrán obtenerse resultados contraproducentes. Hay propaganda también que, si puede dar buenos frutos en un país, en cambio, resultaría inconveniente en otros y sólo crearía asperezas, como ya ha ocurrido, en nuestras relaciones internacionales. ${ }^{31}$

Estas sutilezas sobre lo que resultaba conveniente difundir en cada país sólo podían conocerlas, desde luego, quienes se relacionaran directamente con sus habitantes, como ocurría con los funcionarios del servicio exterior. En segundo lugar, Hay dudó de la prioridad que el DAPP le otorgaría al asunto. Insistió en que la distribución de propaganda en los países extranjeros era un tema de especial importancia para su Secretaría, mientras que para el DAPP "no se relaciona más que con una de las tan variadas aunque importantes funciones de su departamento" ${ }^{32}$

Al parecer, Hay no se limitó a quejarse ante Agustín Arroyo Ch., sino que también realizó fructíferas gestiones ante el Ejecutivo. Lo cierto es que a pocas semanas de entrado en funcionamiento el DAPP, Cárdenas reconsideró la distribución de roles inicial. Con fecha 19 de enero de 1937, el presidente firmó un acuerdo en que se fijaba la participación que tendría la Secretaría de Relaciones

${ }^{31}$ De Ernesto Hay, secretario de Relaciones Exteriores (en adelante EH) a AACh, 20.1.1937, FAACh, gaveta 3, carpeta “A/30/-1 DAPP”.

32 De EH a AACh, 20.1.1937, FAACh, gaveta 3, carpeta “A/30/-1 DAPP”. 
Exteriores en la propaganda hacia el exterior. Aunque no le devolvió todas sus atribuciones previas, el acuerdo presidencial revocó la absoluta supremacía del DAPP sobre la propaganda dirigida al extranjero y estableció que, en este campo, el nuevo departamento habría de actuar en conformidad con la SRE. ${ }^{33}$ Según esta redefinición, y la de otras disposiciones presidenciales que se fueron sumando después, el DAPP seguiría elaborando el material de propaganda y enviaría información por radio y boletines de noticias a todos los representantes de México en el exterior, pero sería la SRE quien visaría los contenidos de la propaganda enviada al extranjero e instruiría a los funcionarios del servicio exterior sobre la implementación de las campañas. ${ }^{34}$ La SRE, de hecho, se preocupó de resguardar su autoridad sobre cónsules y embajadores, insistiendo en que de acuerdo con la Ley del Servicio Exterior, toda comunicación entre los consulados y embajadas con el DAPP, o cualquier otra dependencia del Ejecutivo, debía realizarse por conducto de la Secretaría de Relaciones Exteriores. Arroyo Ch. se resistió quejándose de que dicho procedimiento entorpecía las comunicaciones y pidió que los consulados pudieran escribirle directamente, pero el subsecretario Ramón Beteta se mantuvo firme en la defensa de sus atribuciones. ${ }^{35}$ Beteta también se preocupó de extender el control de la SRE sobre las campañas realizadas por otros organismos, indicando al Partido Nacional Revolucionario que toda la propaganda realizada por ellos en el extranjero debía ser distribuida previa consulta con dicha secretaría. ${ }^{36}$

Con todo, la expropiación petrolera dictaminada por Cárdenas en marzo de 1938 volvió a fortalecer el rol del DAPP en relación a la propaganda exterior, al menos temporalmente. Aunque no se encontraron documentos que confirmen una denominación formal por parte del gobierno, todo indica que ante la

33 De AACh a Emilio Portes Gil (en adelante EPG), 17.1.38, FAACh, gaveta 8, Carpeta “1938”; EH a AACh, 27.8.1938, AGN DGI (I) caja 175, 301.60/270.

34 De AACh a Cónsul Berkeley, 16.2.1937, AGN DGI (I), caja 142, Exp. 301(73-89)/1; De AACG a EPG, 17.1.1938, FAACh, gaveta 8, carpeta "1938"; De EH a AACh, 27.8.1938, AGN DGI (I) caja $175,301.60 / 270$.

35 De AACH a Secretaría de Relaciones Exteriores (en adelante SRE), 20.4.1937, AGN DGI (I), caja 49, Exp. 201(019)/2; De Ramón Beteta, subsecretario de Relaciones Exteriores (en adelante RB) a AACh, 26.4.1937, AGN DGI (I), caja 49, Exp. 201(019)/2; De AACh a SRE, 29.4.1937, AGN DGI (I), caja 49, Exp. 201(019)/2.

${ }^{36}$ De RB a Silvano Barba Gonzalez, presidente del PNR, 16.3.1937, AHGE III-166-17. 
necesidad de implementar a gran escala un plan de propaganda que justificara la medida y contrarrestara las campañas de sus adversarios en Estados Unidos, durante los primeros meses recayó sobre el DAPP la misión de coordinar dicha labor. Arroyo Ch. se preocupó de solicitar a los propagandistas mexicanos que estaban actuando en forma autónoma o reportándole a la SRE, que le informaran a él de sus actividades, ${ }^{37}$ e incluso las autoridades de la SRE reportaron al DAPP acerca de las intensas labores de proselitismo que durante ese período realizaron en territorio norteamericano..$^{38}$ No obstante, con el paso de los meses la Secretaría de Relaciones Exteriores fue recuperando cierto control y durante los dos años siguientes continuó exigiendo su derecho a autorizar la propaganda enviada a Estados Unidos, recordándole reiteradamente a Arroyo Ch. el acuerdo presidencial del 19 de enero de $1937 .^{39}$

En suma, la relación de poder entre el DAPP y la SRE ante la propaganda exterior de México fue ambigua. No estuvo claramente delimitada y fue cambiante a lo largo de los tres años que existió el DAPP. Estaba claro que correspondía al DAPP elaborar el material de propaganda y a la SRE coordinar su distribución. Más confuso fue establecer quién diseñaba las estrategias y tomaba las decisiones sobre cómo desarrollarlas, y en ello hubo un empoderamiento vacilante que osciló entre ambas dependencias. Aunque la SRE habría debido poder visar el contenido de películas y publicaciones, no existieron instancias formales para que ejerciera dicha revisión en forma previa a su envío hacia el exterior. Por lo demás, aunque se establecieran oficialmente ciertos conductos regulares de comunicación, estos muchas veces no eran respetados: el DAPP escribía

37 A mediados de 1938, el encargado de la propaganda extranjera del PNR, Salomón de la Selva, quien estaba realizando una gira de publicidad por Estados Unidos de la cual reportaba a la SRE, le envió a Agustín Arroyo un detallado informe sobre sus actividades luego de que éste así se lo solicitara. Salomón de la Selva, Memorándum para el sr. Lic. Don Agustín Arroyo Ch., 20.7.1938, AGN P LCR, 543/244.

${ }^{8}$ En abril de 1938, el embajador en Perú Moisés Sáenz obró bajo instrucciones directas de Agustín Arroyo en su gira de propaganda por EEUU, e incluso el subsecretario Ramón Beteta se supeditó al departamento, consultándole a su director si debía o no aceptar la invitación a realizar determinadas conferencias pro México en Estados Unidos. De AACh a LCR, 7.6.1938, AGN LCR 704.1/189; De Moisés Saenz a AACh, 5.4.1938, FAACh, archivador “abril-mayo 1938”, gaveta 8; De RB a AACh, 5.4.1938, FAACh, archivador “abril-mayo 1938”, gaveta 8.

$39 \mathrm{EH}$ a AACh, 27.8.1938, AGN DGI (I) caja 175, 301.60/270. 
directamente a los cónsules, la Secretaría de Prensa y Propaganda del PNR le enviaba publicaciones directamente al embajador en Washington, ${ }^{40}$ y los propagandistas y representantes en Estados Unidos reportaban simplemente a aquella autoridad con quien tuvieran más afinidad.

\section{La propaganda exterior del DAPP: aportes y limitaciones}

Dentro de la ambigua y oscilante división de roles con la SRE, el DAPP influyó positivamente en algunos aspectos de la propaganda exterior, destacando especialmente en la generación de material impreso y audiovisual de propaganda para ser utilizado en la diplomacia pública. Al ser el responsable de elaborar el material que se enviara fuera de México, pudo controlar el contenido de publicaciones y películas, unificando sus criterios y asegurándose de que sus argumentos fueran congruentes con la postura oficial. La elaboración de material de propaganda por parte del DAPP tuvo como consecuencia, además, un aumento en la cantidad y calidad de las publicaciones enviadas al extranjero. El departamento centralizó en los Talleres Gráficos de la Nación, que había quedado bajo su cargo, todos los servicios y presupuestos de impresión que manejaban hasta la fecha las diversas secretarías, lo que le permitió perfeccionar sus técnicas y producir grandes tirajes. Además, puso especial atención en la calidad de sus impresiones y en el diseño de las distintas piezas gráficas, contratando a profesionales para ese fin. ${ }^{41}$ Se priorizó una estética sobria y un estilo unificado entre las distintas publicaciones, atributos que fueron sumamente valorados por los representantes de México en el exterior. ${ }^{42}$

Aunque la elaboración de material de difusión del DAPP estuvo orientada principalmente a la propaganda interior, también se produjeron algunas piezas

$4^{\circ}$ De Gilberto Bosques, secretario de Prensa y Propaganda del PNR, a FCN, 1.10.1937, AHGE APFCN 17.

41 "Proyecto de Organización del Departamento Autónomo de Propaganda y Publicidad", 29.12.1936, APIP, carpeta 16, 90/158m, cartón 1; Carlo Mata y Luis Cardoza y Aragón, “Plan de Trabajo de la Oficina Editorial del Departamento Autónomo de Publicidad y Propaganda”, enero 1937, APIP, carpeta 14, 90/158m, cartón 1; DAPP (1937), Memoria, p. 79, 80.

$4^{2}$ De Moisés Saenz, embajador de México en Perú, a AACh, 11.8.1937, FAACh, carpeta “junio de 1937", gaveta 7.

ESTUDIOS DE HISTORIA MODERNA Y CONTEMPORÁNEA DE MÉXICO 55, enero-junio 2018, 279-312 DOI: http://dx.doi.org/10.22201/iih.24485004e.2018.55.63301 
destinadas a audiencias foráneas. La mayoría fueron traducciones de los mismos folletos que hicieron circular dentro del país, aunque algunas publicaciones fueron especialmente elaboradas para el público extranjero. Fue el caso, por ejemplo, de folletos turísticos como Valley of Mexico y Down to Mexico in your own car; del libro que recopilaba conferencias del subsecretario Ramón Beteta, The Mexican Revolution: a defense (el cual fue luego traducido al español); del folleto fotográfico sobre la labor del gobierno México en Acción, editado en formato trilingüe con textos en inglés, francés y español; y de la revista Mexican Art \& Life, publicada sólo en inglés. Ésta, cuya edición quedó a cargo del poeta y excomisionado de publicidad en Nueva York José Juan Tablada, se publicó entre 1938 y 1939 y tuvo un contenido principalmente cultural. La revista destacó especialmente debido a la calidad de sus contenidos, su atractivo y colorido diseño gráfico y su cuidada impresión, convirtiéndose en la favorita de diplomáticos y otras personalidades para distribuir en el exterior y siendo algunos de sus artículos reproducidos espontáneamente por la prensa norteamericana. ${ }^{43}$ El material en inglés impreso por el DAPP se multiplicó tras la expropiación petrolera, luego de la cual se editaron numerosos libros y folletos en ese idioma que explicaban la postura oficial del gobierno mexicano y justificaban su actuar, tales como la traducción de los discursos de Cárdenas acerca de la medida y del dictamen de la Corte Suprema respaldándola, ${ }^{44}$ o el libro The mexican people and the oil conflict de Alejandro Carrillo.

Con todo, la mayor contribución del departamento a la diplomacia pública fue su nutrida producción cinematográfica, ámbito en el que efectivamente realizó un aporte novedoso y rupturista. A través de su Sección de Producción Cinematográfica, dirigida por el cineasta Gregorio Castillo, contribuyó a la

43 De Abraham Mejía a Jefe del Servicio de Información de la Secretaría de Gobernación, 14.6.1940, AGN DGI (I), caja 142, exp. 301(78-44)/1; de Moisés Saenz, embajador de México en Perú, a AACh, 11.8.1937, FAACh, carpeta "junio de 1937", gaveta 7; de Gustavo Ortiz Hernán, cónsul en Filadelfia, a AACh, 25.7.39, FAACh, Archivador "julio 1939-sept 1939", gaveta 6; De Pedro de Alba, presidente se la Unión Panamericana, a AACh, 6.12.1938, FAACh, carpeta 'A' años 1938-1939-40-...", gaveta 22; de Fritz Aufhold, AYH Travel Service, a José Juan Tablada, 6.12.1938, AGN DGI (I), caja 127, exp. 300/454; De Peter Horton a DAPP, 15.9.1939, AGN DGI (I), caja 128, exp. 300/585.

44 Decision Rendered by the Supreme Court of Mexico in the Oil Expropiation Case (Mexico, D. F., 1940). 
modernización de las campañas de propaganda exterior al incorporar los modernos medios de comunicación de masas que estaban siendo explotados por los gobiernos europeos y norteamericano. Así, aunque las administraciones mexicanas anteriores habían mostrado registros cinematográficos sencillos en otros países, y durante el sexenio cardenista la Secretaría de Educación Pública (SEP) elaboró una importante cinta de propaganda, como fue Redes, ${ }^{45}$ fue el DAPP el que implementó la infraestructura y organización necesaria para elaborar películas de propaganda gubernamental en forma sistemática, produciendo en poco tiempo una gran cantidad de cintas documentales que promovían la obra de la administración cardenista. ${ }^{46}$ Con ocasión de la expropiación petrolera el departamento fue capaz de reaccionar en forma rápida y editar en corto tiempo películas que difundían el punto de vista mexicano en el conflicto, sobresaliendo en este aspecto en la "guerra de propaganda" con las petroleras, las cuales no utilizaron este medio tras la expropiación. ${ }^{47}$ La utilización del cine en la diplomacia pública mexicana tuvo además consecuencias sobre la naturaleza misma de las campañas, al incorporar nuevos lenguajes persuasivos que apelaban a un estado sicológico más emocional y sugestivo que los logrados a través de charlas y folletos.

Sin embargo, pese a estos aportes la labor del DAPP presentó una serie de desaciertos y limitaciones en cuanto a propaganda exterior. En gran parte, estos tuvieron relación con lo que paradojalmente era entendido como el principal mérito del departamento, como fue la centralización de toda labor de propaganda oficial bajo un mismo organismo. Ello derivó, en primer lugar, en que el DAPP se viera desbordado por sus múltiples responsabilidades, que abarcaban lo que antes estaba distribuido entre diversas secretarías y dependencias. Pese a su mayor dotación de presupuesto y personal, sus tareas resultaron ser tan numerosas y variadas que, unido a una excesiva burocratización, su labor

45 La cinta argumental Redes (1936), producida por la SEP con guión y dirección de fotografía del cineasta norteamericano Paul Strand, mostraba la vida y lucha de los pescadores del Puerto de Alvarado, en Veracruz.

${ }^{46}$ Sobre las películas cinematográficas elaboradas por el DAPP, véase Ruiz Ojeda (2012)

47 El DAPP editó tres cintas sobre el conflicto petrolero, cuya versión en inglés hizo circular especialmente por Estados Unidos: “La Nacionalización del Petróleo" (1938), “México y su Petróleo” (1938) y “El Petróleo Nacional” (1939). 
muchas veces fue lenta e ineficiente. ${ }^{48}$ Por lo demás, y tal como había advertido el secretario Hay, la propaganda exterior no fue la principal prioridad del departamento. La misión de unificar ideológicamente a la población mexicana y mantenerla comprometida con la obra del gobierno fue entendida como su objetivo principal, apareciendo la publicidad hacia el extranjero como parte de una instancia secundaria y posterior (al menos, hasta la expropiación petrolera). ${ }^{49}$

La esperanza de que el DAPP lograra coordinar todo el programa de diplomacia pública bajo un plan central rigurosamente elaborado tampoco se cumplió. El departamento efectivamente fue celoso de que la información que se entregara al público exterior se circunscribiera al criterio oficial, pero, más allá de supervisar el contenido, no destacó en la elaboración de planes coordinados y a gran escala que propusieran una visión de largo plazo y una encadenación de actividades, como había tenido por intención la Oficina Técnica. Su centralización fue, de hecho, más burocrática que de planificación.

Finalmente, la centralización geográfica del DAPP también trajo costos a la propaganda exterior. El departamento comandaba todas sus actividades desde sus oficinas en la calle Bucareli de Ciudad de México, incluidas aquellas orientadas al extranjero. Aquel aspecto de la organización podría haberse resuelto en forma distinta, ya que en las instancias de planificación del nuevo organismo de propaganda se había considerado la posibilidad de crear una figura especial para la propaganda exterior. Un anteproyecto elaborado cuando se diseñaba la Dirección de Publicidad y Propaganda (DPP) en 1936 -dependencia que dio paso luego al DAPP-,$^{50}$ proponía la creación de "secciones extranjeras" de dicho organismo. Estas funcionarían con cierta autonomía, colaborando tanto con dicha dependencia como con los consulados de sus jurisdicciones. Además, sus delegados estarían en condiciones de desarrollar iniciativas y resolver problemas

${ }^{48}$ Entre los papeles del DAPP se acumulaban las quejas de terceros por correspondencia no contestada, material de propaganda no despachado o la espera de horas, e incluso días, para ser -o no- recibido por algún representante del departamento.

49 “Decreto", de A. García Toledo a AACh., 1.1.1937, AGN DGI, caja 7, 101.1/1; de API a H. C. Halley, 20.1.1938, AGN DGI (I), caja 124, 300/59.

50 Véase nota n. 17. 
no previstos en el propio terreno, sin tener que esperar órdenes desde México. ${ }^{51}$ Por cierto, así era como funcionaban los organismos centralizados de propaganda más importantes de otros países: tanto el Committee on Public Information norteamericano durante la Primera Guerra Mundial como el Ministerio de Goebbels en Alemania contaban con secciones extranjeras o, al menos, con encargados de propaganda adscritos a sus embajadas en el exterior. ${ }^{52}$ Incluso algunos gobiernos mexicanos anteriores habían organizado oficinas de ese tipo en Estados Unidos. ${ }^{33}$ Sin embargo, esta iniciativa no se materializó bajo el DAPP, y su director Agustín Arroyo Ch. parecía sentirse cómodo así, rechazando todas las propuestas que se le hicieron de crear oficinas del DAPP -O “dappitos", como se les llegó a llamar- en el extranjero. ${ }^{54}$ Tal centralización geográfica, aparte de evidenciar cuáles eran las prioridades del departamento, tuvo importantes consecuencias. No sólo porque las comunicaciones y envíos de material hacia el extranjero eran sumamente lentos y engorrosos - problema al cual, en realidad, también debía enfrentarse la SRE al coordinar el trabajo de su servicio exterior-, sino especialmente por lo desconectado que resultaba el DAPP de las necesidades y características de la propaganda exterior. Los funcionarios del departamento no tenían conocimientos especiales acerca del público extranjero y los objetivos de México hacia el exterior -como sí los tenía la SRE-, por lo que su alejamiento geográfico no hacía más que exacerbar la falta de comprensión sobre este tema. Ello derivó en uno de las principales limitaciones del DAPP a la hora de realizar diplomacia pública: sus fallas en lo que podría denominarse como "mediación cultural".

51 “Bosquejo de funciones de la Dirección General de Publicidad”, APIP, carpeta 13, 90/158m, cartón 1.

52 Creel (1920); Chang (2014, p. 574).

53 Carranza estableció en Estados Unidos un Bureau of Information encargado de su diplomacia pública (Smith, 1995, p. 155-174).

54 De Rafael de la Colina, cónsul en NY, a AACh, 8.7.1937, FAACh, carpeta “junio de 1937”, gaveta 7; de José Miguel Bejarano a AACh, 16.7.1937, AGN DGI (I), caja 124, 300/102; de José Miguel Bejarano a Secretaría Personal de la Presidencia, 16.7.1937, AGN P LCR, 533.2/35; de Gustavo Ortiz Hernán, cónsul en Filadelfia, a Rafael Rionda, 14.10.1939, FAACh, Carpeta “O’años 1932-33-34-35-36...”, gaveta 19; de R. A. Maier a AACh, 30.3.1938, FAACh, archivador “abril-mayo $1938 "$, gaveta 8 . 


\section{El DAPP y la SRE ante el desafío de la mediación cultural}

La mediación cultural ha sido definida por Ronald Taft como el acto de facilitar la comunicación, el entendimiento y la acción entre grupos que difieren respecto a su lenguaje o cultura, para lo cual deben interpretarse las expresiones, intenciones, percepciones y expectativas de cada grupo cultural para el otro. ${ }^{55} \mathrm{Al}$ darse en un contexto intercultural, la propaganda exterior de México requería de un elaborado trabajo de mediación cultural para ser efectiva. Había que adaptar el mensaje deseado al público extranjero que se buscaba convencer, a fin de hacerlo comprensible y aceptable. Dicha traducción debía realizarse, en primer lugar, a nivel formal, considerando el idioma de cada país receptor, el lenguaje periodístico correcto y el tono sicológico apropiado para cada cultura. Luego, había que saber adaptar el mensaje en el plano de las ideas, utilizando conceptos y valores que resultaran aceptables para la sensibilidad del público local y, por sobre todo, evitando aquellos que pudieran generar rechazo. Este trabajo de interpretación y adaptación requería no sólo de la capacidad de entender y compenetrarse con la postura mexicana a difundir, sino que exigía también un profundo conocimiento del público extranjero que se quería alcanzar. Como señala Taft, el mediador cultural es alguien que debe poder participar hasta cierto punto en ambas culturas, conociendo desde el contenido de sus sistemas de creencias hasta los aspectos formales de sus estilos de comunicación. ${ }^{6}$

Hasta la fecha, el rol de mediadores culturales entre México y los demás países lo habían ejercido principalmente los cónsules mexicanos en el exterior, apoyados en algunas ocasiones por propagandistas privados -mexicanos o extranjeros- que se movían bien entre la cultura mexicana y la del país en que ejercían su labor. ${ }^{57}$ Ellos hacían de intérpretes, adaptando el mensaje a la cultura local y manteniendo a la SRE informada sobre las necesidades y sutilezas de la

55 Taft, R. (1981, p. 53, 57), citado en Katan (2014, p. 17).

${ }^{56}$ Taft, R. (1981. p. 53, 57), citado en Katan (2014, p. 17).

${ }^{57}$ Entre los propagandistas privados que trabajaron para la SRE desde EEUU durante el cardenismo se encontraban José Juan Tablada, José Miguel Bejarano, Salvador Mendoza y Margarita Álvarez de Mendoza. 
propaganda que podría funcionar en cada país o, más específicamente, en cada localidad. La directiva del DAPP, sin embargo, no supo valorar en su real dimensión el aporte de estos intermediarios. De hecho, al entrar en funcionamiento optó por prescindir de la colaboración de los propagandistas privados en el exterior en los que se había estado apoyando la SRE, argumentando que no necesitaban de "ayudas extrañas" para ejercer sus labores y advirtiendo que resultaba difícil controlar el real compromiso ideológico de terceros. ${ }^{58} \mathrm{El}$ DAPP sacrificó así el aporte de estos colaboradores -su expertise profesional, su conocimiento del público extranjero y su valiosa condición de publicistas independientes sin aparente conexión oficial- en nombre de su centralismo burocrático. En relación a los cónsules de México, aunque estos siguieron siendo los encargados de implementar las campañas y distribuir el material de propaganda en el extranjero, el departamento de Arroyo $\mathrm{Ch}$. fue muchas veces reacio ante sus propuestas, desestimando altaneramente y con bastante falta de visión la mayoría de sus sugerencias.

Aquella falta de visión se fundaba, probablemente, en el hecho de que la dirección del DAPP no otorgó real importancia a la diferenciación entre audiencias mexicanas y extranjeras, ni menos, a la diferenciación entre públicos de distintos países. El DAPP se tomó muy literalmente su misión de unificar el contenido de todas las comunicaciones del Ejecutivo bajo un mismo criterio oficial, y en este proceso perdió de vista la importancia de adecuar el mensaje a cada público particular. Pese a que en los escritos de la Oficina Técnica se reconocía la importancia de adaptar el mensaje a las distintas audiencias, en la práctica no se le dio prioridad. De hecho, muy pocas de las publicaciones distribuidas por el departamento entre audiencias foráneas fueron especialmente redactadas

${ }^{58}$ Memorándum, de Margarita Robles de Mendoza a AACh, 21.1.1937, AGN DGI, caja 51, exp. 11/30(02)/3; de Salvador Mendoza a Ignacio García Téllez, 13.5.1937, AGN P LCR 702.2/479; de Secretario Particular de la Presidencia a Salvador Mendoza, 27.6.1939, AGN P LCR 162/2; de Rafael de la Colina, cónsul en NY, a AACh, 8.7.1937, FAACh, carpeta "junio de 1937", gaveta 7; de José Miguel Bejarano a AACh, 16.7.1937, AGN DGI (I), caja 124, exp. 300/102; de José Miguel Bejarano al Secretario Particular de la Presidencia, 16.7.1937, AGN P LCR, 533.2/35; de JRPC a José Miguel Bejarano, 21.8.1937, AGN P LCR 533.2/35; de Estela Sanginés Villalva, Economista "B", sección de economía, al jefe de la oficina técnica de la DAPP, Dictamen, 29.1.1937, AGN DGI, caja 51, 11/30(02)/3; J. Rodolfo Lozada, "Dictamen sobre el ofrecimiento que hace... Bill Gray", 8.4.1937, AGN DGI, caja 51, 30(02)/9. 
para ellas. Por lo general se trató de simples traducciones de los textos elaborados para circulación nacional, o, incluso, de esos mismos impresos en español. Por cierto, hubo algunas honrosas excepciones, como el folleto México en Acción y la revista Mexican Art \& Life, que por el hecho de haber sido concebidos -tanto a nivel de contenido como de idioma y diseño- para un público extranjero, lograron una buena acogida entre éste. El hecho de que el editor de Mexican Art\&Life, el poeta José Juan Tablada, haya ejercido previamente como propagandista privado para la SRE mientras residía en Estados Unidos, refuerza la idea de que para elaborar material de propaganda exterior se requería de especialistas compenetrados en los requerimientos de la mediación cultural. Sin embargo, no fue la regla dentro del DAPP.

Tampoco los documentales elaborados por el DAPP cumplieron con estos requisitos. Las cintas confeccionadas para mostrar en México simplemente se doblaban al inglés o francés para ser distribuidas en el exterior. Incluso, algunas películas se hicieron circular en Europa y Estados Unidos solamente en español, fallando con ello en uno de los aspectos más básicos de la mediación cultural, como es la traducción al idioma local. Pese a las recomendaciones de diversos expertos, a Agustín Arrollo Ch. aquello no le parecía especialmente grave. Ante las advertencias que hiciera un cónsul de México en Estados Unidos sobre lo inconveniente que resultaba difundir en ese país la película Redes en español, Arroyo argumentó que las situaciones interpretadas en la cinta podrían ser interpretadas y valorizadas "de todas formas" por espectadores que no hablaran ese idioma, sobre todo en el aspecto estético. ${ }^{59} \mathrm{El}$ jefe del DAPP ni siquiera parecía darse cuenta del inconveniente que aquello podía significar en el intento por alcanzar a la opinión pública foránea.

Uno de los más claros ejemplos de la falta de diferenciación entre el público interno y externo resultaron ser los boletines informativos del DAPP. La tarea de suministrar a los medios foráneos noticias favorables a México había sido una de las principales misiones encomendadas al DAPP para mejorar la imagen del país en el exterior y era considerada, de hecho, uno de los mecanismos más

59 La distribución de la cinta Redes, producida por la SEP en 1936, quedó a cargo del DAPP una vez que este entró en funcionamiento. De DAPP, sin destinatario, sin fecha, AGN DGI (I), C177, $301.66(07) / 3$. 
importantes para revertir la mala prensa internacional del país. ${ }^{60} \mathrm{Y}$ aunque el DAPP fue muy prolífico en la creación de noticias, no supo adaptarlas a los intereses y necesidades de la opinión pública extranjera. Sin ir más lejos, reemplazó el Noticiero Semanal de la SRE, que publicaba en inglés, francés y español columnas especialmente redactadas para una audiencia foránea, por su Boletín de Información, impreso confeccionado originalmente para enviar a los periodistas mexicanos, que se publicaba solamente en español y contenía noticias de carácter tan localista que resultaba de escaso interés para los medios de prensa extranjeros. Pese a que los cónsules en el exterior se quejaban de no lograr insertar dichas noticias en la prensa de sus localidades por su escaso atractivo periodístico, y pedían que el boletín se les enviara en inglés, Arroyo no hizo eco de aquellas solicitudes, manifestando que aquello resultaría "antieconómico y extemporáneo" para el DAPP. ${ }^{61}$

La dirección del DAPP tampoco se preocupó de no pasar a llevar los valores e ideologías de la opinión pública extranjera. Esta carencia en la mediación cultural resultó particularmente grave, ya que con ella no solo arriesgaba obtener incomprensión o desinterés, sino que podía incluso generar más rechazo hacia la causa de México. Ello ocurrió porque el departamento no siempre supo -o quiso- filtrar correctamente el mensaje ideológico del material de propaganda que generaba para la población mexicana al enviarlo al exterior. La poca disposición del DAPP de respetar la sensibilidad de ciertas audiencias extranjeras se manifestó especialmente tras la expropiación petrolera de 1938, en donde el discurso triunfalista y de fuerte nacionalismo que fue promovido por el gobierno hacia las masas de mexicanos, permeó también la propaganda que el DAPP dirigía hacia la opinión pública norteamericana para justificar la medida. ${ }^{62}$ Ante ello, varios cónsules de México en Estados Unidos hicieron ver la necesidad de no herir susceptibilidades en ese país y realizaron un esfuerzo deliberado por ser

${ }^{60}$ De LCR a SCU, 25.12.1936, AGN LCR 545.2/33.

${ }^{61}$ De Cónsul de San Diego a DAPP, 25.2.1937, AGN DGI (I) caja 142, 301(73-47)/1; de José Rivera P. C. a SRE, 10.6.1937, AGN DGI (I), caja 49, 201(019)/3; de AACh a SRE, 21.4.1938, FAACh., gaveta 25, carpeta ““H”, años 1932-...-1955”; de Legación de México en Nicaragua a AACh, 7.7.37, FAACh, carpeta "junio de 1937 ", gaveta 7.

62 Sobre la propaganda del DAPP hacia el público mexicano tras la expropiación petrolera, véase González Salinas (2016). 
más moderados en su tono que el que utilizaba el DAPP. ${ }^{63}$ Sin embargo, el departamento de Arroyo Ch. no fue sensible a tales sutilezas. Ilustrativa fue la polémica que se generó en torno al documental del DAPP La nacionalización del petróleo, que registraba las masivas manifestaciones de apoyo a la expropiación que se dieron en ciudad de México pocos días después del anuncio presidencial. Su versión en inglés fue profusamente exhibida en Estados Unidos porque en el DAPP se consideró que la cinta sería allí "el más eficaz medio para establecer una corriente de simpatía y buena comprensión de los sentimientos que animan a nuestro país en asuntos de tanta trascendencia” ${ }^{64}$ No obstante, el cónsul de México en Chicago, Rodolfo Salazar, expresó un diagnóstico totalmente opuesto. Planteó a sus superiores la inconveniencia de exhibir el documental en Estados Unidos por el hecho de que la opinión pública norteamericana no estaba todavía solidarizada con el acto de expropiación e importantes sectores del país censuraban la medida. Salazar insistió que el documental no haría más que avivar esas diferencias y generaría una reacción hostil entre el público norteamericano, algo que él mismo había podido comprobar luego de organizar una exhibición privada de la película con comerciantes, industriales y autoridades de ese país. ${ }^{65}$ Sin embargo, las aprehensiones del cónsul no fueron tomadas en serio por el jefe del DAPP. Arroyo Ch. se molestó con la misiva y se mostró contrario a sus observaciones. Desde una clara falta de sintonía con el público de Estados Unidos, argumentó que las películas del DAPP no ofendían a ninguna nacionalidad, sino, cuando mucho, a la sensibilidad de determinados inversionistas en México, e insistió en la necesidad de que se conociera en el extranjero el respaldo del pueblo mexicano al gobierno. Contradiciendo al cónsul Salazar, su conclusión

63 Aquella preocupación pudo verse, por ejemplo, en las celebraciones que los consulados de México en Estados Unidos organizaron para los aniversarios de la expropiación petrolera en sus circunscripciones. De Efraín Domínguez, cónsul en Laredo, al cónsul general en San Antonio, 14.3.1940, AHGE L-E-556; de Omar Josefé, cónsul en San Antonio, al secretario de RREE, 25·3.1940, AHGE L-E-555; de Carlos A. Calderón, Brownsville, a cónsul general en San Antonio, 15.3.1940, AHGE L-E-556.

64 Oficio, del DAPP a la SRE, 11.5.1938, transcrito en de Víctor Táfel, Portland, Oregon al cónsul Milwaukee, 17.10.1938, AHGE L-E-559.

${ }^{65}$ De EH a AACh., 4.7.1938, AGN DGI (I) caja 173, 301.60/89; de Rodolfo Salazar, cónsul en Chicago, a SRE, 20.7.1938, AGN DGI (I) caja 173, 301.60/89. 
fue que películas de ese tipo debían ser exhibidas con mucha mayor fuerza en el exterior. ${ }^{66}$

La limitada visión estratégica de Agustín Arroyo Ch. en cuanto a diplomacia pública hacía aparecer como justificadas las aprensiones que el secretario de Relaciones Exteriores Eduardo Hay había planteado a Cárdenas, ante la creación del DAPP, acerca del necesario conocimiento sobre audiencias foráneas que requería la propaganda exterior. ${ }^{67}$ La polémica en torno al documental avivó la falta de confianza de Hay hacia el criterio de Arroyo Ch., por lo que le sugirió al jefe del DAPP que, "en vista de la situación actual de las relaciones entre México y los Estados Unidos", las películas enviadas a ese país por el departamento se exhibieran previamente ante algún representante de la Secretaría de Relaciones Exteriores, con el objeto de prevenir cualquier contingencia. A este propósito le recordó el Acuerdo del 19 de enero de 1937 firmado por el presidente Cárdenas. ${ }^{68}$

El reclamo de Hay respondía al hecho de que la SRE, efectivamente, conocía con mayor profundidad los intereses y sensibilidades del público externo, gracias a la constante retroalimentación que recibía en ese sentido por parte de los miembros de su servicio consular. No obstante lo anterior, era además el organismo mejor compenetrado acerca de las necesidades estratégicas de México en política exterior, cuya naturaleza difería de las políticas domésticas. La SRE comprendía mejor que el DAPP que la diplomacia pública perseguía objetivos distintos a los de la propaganda interior cardenista: no buscaba unificar ideológicamente a sus audiencias ni obtener la colaboración activa de éstas en el desarrollo de las reformas, sino simplemente despertar una actitud comprensiva y favorable hacia la implementación del Plan Sexenal para protegerlo, en última instancia, del intervencionismo extranjero. Se orientaba por tanto hacia la colaboración con otros gobiernos antes que a la confrontación. En el caso de la expropiación petrolera, por ejemplo, la administración de Cárdenas estaba llevando intensas negociaciones con el gobierno de Estados Unidos para llegar a un acuerdo acerca de cómo se resolvería el conflicto, y para ello requería que las autoridades norteamericanas estuvieran dispuestas a empatizar con la

\footnotetext{
${ }^{66}$ De AACh a EH, 19.7.1938, AGN DGI (I) caja 173, 301.60/89.

67 De EH a AACh., 20.1.1937, FAACh, gaveta 3, carpeta “A/30/-1 DAPP”.

68 EH a AACh, 27.8.1938, AGN DGI (I) caja 175, 301.60/270.
} 
postura mexicana. ${ }^{69}$ Considerando que las campañas de propaganda que estaba implementando tenían como objetivo influir indirectamente sobre las autoridades de Estados Unidos a través de las presiones que, a favor de México, pudiera ejercer la opinión pública de ese país, había que evitar a toda costa enemistarse con esta última.

Dados estos antecedentes, la SRE supo valorar los requerimientos de la mediación cultural, priorizando el buen entendimiento con la opinión pública de otros países por sobre los exaltados términos triunfalistas y nacionalistas presentes en el discurso oficial del gobierno hacia el interior del país. La Secretaría instruyó reiteradamente a sus representantes en el exterior sobre la conveniencia de evitar todo tipo de polémicas o controversias que generaran suspicacias en el exterior. ${ }^{70}$ Para lograr este objetivo, debió además hacer valer su rol de garante del prestigio exterior del país no solo ante el DAPP, sino también ante otros organismos o dependencias gubernamentales que, desde Ciudad de México y con la misma ignorancia sobre diplomacia pública que el departamento de Agustín Arroyo Ch., enviaban material de propaganda hacia el extranjero sin sopesar sus posibles consecuencias. Fue el caso, por ejemplo, de ciertos textos escolares enviados por la SEP a las escuelas donde asistían las colonias de mexicanos en Estados Unidos, los cuales en 1939 despertaron el rechazo de las autoridades norteamericanas locales por su contenido de marcado corte comunista, contrario a los "valores americanos". Pese a la insistencia del secretario de Educación Pública, que abogaba por mantenerlas, Hay optó por ordenar a los cónsules de las distintas circunscripciones norteamericanas que retiraran de las escuelas los libros que provocaran suspicacias, fueran estas "fundadas o no".$^{71}$ En la encrucijada de optar por fortalecer el compromiso ideológico de las

69 Sobre las relaciones diplomáticas entre México y Estados Unidos tras la expropiación petrolera, véase Meyer (1972).

70 SRE, "Instructivo confidencial para los funcionarios consulares mexicanos", circular n. IV-11-31, 8.4.1936, AHGE APFCN 98; de Efraín Domínguez, cónsul en Laredo, al cónsul en general San Antonio, 14.3.1940, AHGE L-E-556; de Rodolfo Salazar, cónsul de México en Chicago, al SRE, 20.7.1938, AGN DGI (I) caja 173, 301.60/89; de Francisco Castillo Nájera, embajador de México en EEUU (en adelante FCN) a LCR, 6.2.1940, AHGE 39-10-2.

${ }^{71}$ De EH a Gonzalo Vázquez Vela, 15.6.1939, SEP Subsecretaría, 27/21; de Gonzalo Vázquez Vela a EH, 21.6.1939, SEP Subsecretaría, 27/21; SRE, “Memorándum para Acuerdo Presidencial”, 1.8.1939, SEP Subsecretaría, 27/21. 
colonias mexicanas o de cuidar su reputación de país moderado en Estados Unidos, la SRE optó por esto último. Del mismo modo, debió intervenir ante la reiterada propaganda de corte político enviado por el Partido Nacional Revolucionario (PNR) a Perú, y que había motivado la protesta formal de las autoridades de ese país, ordenándole a su presidente suspender cualquier propaganda de índole política a los países iberoamericanos y solicitándole que no enviara material al exterior sin previa consulta con la SRE. ${ }^{72}$

Dada su relación permanente con el extranjero, la SRE fue, de este modo, la única dependencia que desde sus oficinas en México comprendió a cabalidad la necesidad de adaptar las campañas de propaganda exterior a los requerimientos de las audiencias foráneas. La secretaría tendió a ser cuidadosa y priorizó el acercamiento y entendimiento con el público extranjero, aún cuando ello significara transar con los discursos nacionalistas o revolucionarios a los que las demás dependencias no querían renunciar. Con ello, demostró que las advertencias del secretario Hay al presidente Cárdenas al crearse el DAPP, según las cuales sólo un organismo que supiera qué tipo de publicidad podía resultar adecuada en cada país debía hacerse cargo de la propaganda exterior, resultaron ser del todo acertadas. El DAPP y otras dependencias mexicanas no entendieron que la diplomacia pública del país no sólo debía realizar propaganda hacia el exterior, sino que hacerlo, precisamente, con diplomacia. Es decir, con inteligencia, tacto y discreción, considerando la sensibilidad del público foráneo y estudiando la mejor forma de lograr provocar en él la respuesta deseada según los requerimientos de la política exterior.

1940: el fin del DAPP, la creación de la Dirección General de Información y el regreso de la SRE a la propaganda exterior

El DAPP fue suprimido el 31 de diciembre de 1939. Las razones de su desaparición no están claras, dado que prácticamente no hay fuentes disponibles que se

72 De RB a Silvano Barba González, presidente del Partido Nacional Revolucionario, 16.3.1937, AHGE III-166-17. 
refieran a ello, ${ }^{73}$ pero oficialmente se explicó que el departamento se había creado debido a "las urgentes necesidades del momento" y que, a fines de 1939, éste ya había cumplido con su misión. ${ }^{74}$ Por cierto, la situación política de 1940 era muy distinta a la de 1936: la sucesión presidencial y la guerra europea marcaban ahora la agenda y establecían nuevas prioridades. En reemplazo del DAPP se creó la Dirección General de Información (DGI), dependiente de la Secretaría de Gobernación, en la cual continuaron trabajando varios de los responsables del departamento. El reemplazo del DAPP por la DGI supuso un replanteamiento acerca del modelo de oficina centralizada de propaganda que había significado el primero, poniendo fin a dicho breve experimento. ${ }^{75}$ De hecho, muchas de las atribuciones que había acumulado el DAPP no fueron traspasadas a la nueva organización, sino que volvieron a cada secretaría tal como habían funcionado hasta 1936. La DGI conservó la misión del DAPP de unificar el criterio de todas las informaciones y declaraciones de carácter oficial y de generar boletines con noticias acerca de la labor del gobierno para distribuirlos entre los medios nacionales y extranjeros, además de hacerse cargo de la propaganda por radio. ${ }^{76}$ Sin embargo, la nueva dependencia dejó de producir material propio de propaganda. No continuó con la vasta producción editorial desarrollada por el DAPP (cada secretaría se volvió a hacer cargo de sus propias publicaciones) y, aunque

73 Con todo, circulan algunas hipótesis al respecto. Mejía Barquera (2010) sugiere que la eliminación del DAPP se debió a un intento de moderación por parte de Cárdenas para garantizar la sucesión presidencial ante la ola de críticas que desataba el organismo. La idea de que el DAPP se había vuelto muy poderoso y chocaba con otros intereses puede ser plausible, si se considera que se optó por volver a repartir la labor publicitaria entre la DGI y las distintas Secretarías, y volver a supeditar la dependencia a la Secretaría de Gobernación. Sin embargo, lo más probable es que la reorganización del sistema de propaganda gubernamental se haya debido a un conjunto de factores, en el que pesaron no solamente razones políticas sino también de gestión, como sugiere el presente artículo. También en ese sentido, Pilatowski Goñi (2014, p. 127) plantea que el reemplazo del DAPP por la DGI puede haberse debido a la necesidad de agilizar la comunicación, en el contexto de guerra, entre la Secretaría de Gobernación y la sociedad, sin la mediación de un departamento autónomo.

74 LCR, “Mensaje a la Nación”, 1939, AGN LCR 704.1/13.

75 La vida de la DGI fue, de hecho, mucho más larga que la del DAPP y su modelo de oficina centralizada de propaganda, funcionando a lo largo de varias décadas. Para más información sobre la DGI, véase Pilatowski Goñi (2014, p. 126-139).

76 Secretaría de Crédito y Obras Públicas, circular, 3.6.1940, AGN DGI, caja 7, 101.1/1; de LCR al secretario de RREE, 22.5.1940, AGN LCR 161.1/11. 
se hizo cargo de seguir distribuyendo las cintas editadas por el DAPP y de llevar a cabo censura cinematográfica, tampoco conservó una sección de producción de películas. De este modo, las amplias funciones de propaganda del extinto DAPP fueron ahora limitadas a una labor que, aunque seguía teniendo fines persuasivos, se centraba más en lo meramente informativo y se movía principalmente en el ámbito periodístico. Las secretarías, en tanto, recuperaron parte de sus antiguas atribuciones en relación a publicidad. Varias volvieron a implementar oficinas de propaganda como las que tenían hasta 1936 y recuperaron algunas partidas presupuestarias destinadas a ese fin. ${ }^{77}$

El hecho de que el DAPP haya sido reemplazado por un organismo que heredaba algunas de sus características, pero modificaba diametralmente otras, indica que existió un diagnóstico según el cual, aunque se seguía reconociendo la necesidad de su existencia, no se evaluaba del todo bien la forma en que la propaganda gubernamental había sido organizada. Se revela como especialmente cuestionada la centralización de todas las formas de publicidad y el control de cada etapa de su producción bajo una dirección única, en desmedro de la expertise y necesidades específicas de cada secretaría en relación a los temas que le correspondía difundir (por cierto, no sólo la SRE había protestado por la pérdida de sus atribuciones en materia de publicidad al crearse el DAPP; también de la sEP habían surgido quejas similares). La labor de propaganda exterior cayó dentro de ese diagnóstico. Al desaparecer el DAPP, el subsecretario Ramón Beteta manifestó a Cárdenas que la misión de explicar y defender en el extranjero la política interna de México debía corresponder a la SRE, poniendo en entredicho las atribuciones que se le habían dado al extinto departamento. ${ }^{78}$ Tales apreciaciones eran del todo esperables por parte del subsecretario de Relaciones Exteriores; no obstante, opiniones similares surgieron incluso desde dentro del propio DAPP. Rodolfo Lozada, de la Oficina Técnica, había planteado ya en abril

77 Secretaría de la Economía Nacional (1940). Memoria, p. 18-20; de Alfonso Teja Zabre, director general de la DGI, a FCN, 5.4.1940, SRE APFCN 147; de Alfonso Teja Zabre, director general DGI, a William Burton Larsen, 29.1.1940, AGN DGI (I), caja 128, 300/623; de Adolfo Ruiz Cortines a DGI, 26.2.1941, AGN DGI (I), caja 44, 141(S-1)/2; de Donasio Espinoza a Lázaro Cárdenas, 2.1.1940, AGN LCR 545.3/252; de Rodolfo Lozada, jefe del Departamento de Información, DGI, al Cónsul en Brownsville, 14.1.1940, AGN DGI, caja 48, 300/616.

78 De RB a LCR, 4.1.1940, AGN FP LCR, 432.2/253-8. 
de 1938 que las oficinas de propaganda en el exterior encargadas de difundir información no debían depender del DAPP sino de la SRE, "que es la encargada de velar por el prestigio del país, por medio del servicio exterior”. Quizás consciente de las limitaciones del DAPP en ese ámbito, planteó que eran miembros del servicio de la SRE los que deberían encargarse de dirigir la labor de propaganda en el extranjero y vigilar su eficaz ejecución. ${ }^{79}$

La desaparición del DAPP implicó, por tanto, un reempoderamiento de la SRE en cuanto a la propaganda exterior del país. La DGI mantuvo la atribución de ser el órgano que transmitía las informaciones, declaraciones y noticias de carácter oficial a la prensa nacional y extranjera ${ }^{80}$ por lo que se le solicitó a los cónsules en el exterior que prestaran a dicha dirección la misma colaboración que habían prestado anteriormente al DAPP y que acudieran a ella cuando personas o instituciones extranjeras requirieran cualquier tipo de información sobre México. ${ }^{81}$ Sin embargo, la responsabilidad de defender a México en el extranjero y desarrollar sus campañas de propaganda exterior volvió a recaer sobre la SRE. Durante 1940 dicha secretaría tomó activamente en sus manos las acciones para contrarrestar la antipropaganda de las compañías petroleras expropiadas, la cual seguía siendo sumamente agresiva. Para ello trabajó en directa coordinación con el presidente Cárdenas y contó con la colaboración de otras dependencias del Ejecutivo, como la Secretaría de Hacienda y Crédito Público. ${ }^{82}$

\section{Conclusiones}

El experimento cardenista de reunir propaganda interior y exterior bajo un solo organismo resultó ser más complejo de lo esperado. La SRE resistió fuertemente

79 De J. Rodolfo Lozada, Oficina Técnica DAPP, al Oficial Mayor del DAPP, 2.4.1938, AGN DGI (I), caja 126 , exp. vi/300/289.

${ }^{80}$ De LCR al Secretario RREE, 22.5.1940, AGN LCR 161.1/11.

${ }^{81}$ De Alfonso Teja Zabre, director general de la DGI, al cónsul de México en Albuquerque, 12.1.1940, AGN DGI, serie II, caja 48, 300/616.

${ }^{82}$ La Secretaría de Hacienda y Crédito Público se encargó, entre otros aportes, de redactar y financiar el libro The True Facts About the Expropiation of the Oil Companies' Properties in Mexico (1940), en el cual refutaba con argumentos económicos y legales las acusaciones de las compañías petroleras. 
la pérdida de sus atribuciones en el campo de la diplomacia pública y ejerció presiones para recuperarlas, debilitando con ello el rasgo centralizador del nuevo departamento. Por su parte, el DAPP no estuvo a la altura de las enormes expectativas que despertó su creación, al menos en lo relativo a propaganda exterior. Aunque cumplió con mejorar la calidad gráfica de las publicaciones y destacó especialmente en la elaboración de documentales persuasivos, la anhelada "profesionalización" de la propaganda no benefició del todo la implementación de las campañas en el extranjero. La centralización del departamento -cual era, en apariencia, la principal virtud del DAPP- jugó en contra de la diplomacia pública: no sólo porque las campañas internacionales no eran la prioridad del organismo, sino especialmente porque dicho modelo organizacional lo alejaba del mundo exterior. El DAPP no contó con oficinas en el extranjero y tampoco confió en los intermediarios que lo podían ligar con él, por lo que sus directores mostraron un importante desconocimiento del público foráneo. Aquello derivó en que sus campañas fallaran en términos de mediación cultural, elemento imprescindible en cualquier forma de comunicación intercultural que pretenda ser exitosa. Con su falta de sensibilidad hacia los códigos y valores de ciertas audiencias extranjeras, el DAPP arriesgó en ocasiones generar más rechazo que aceptación hacia la causa mexicana, evidenciando como legítimas y atingentes las aprensiones que en ese sentido tuvo la SRE ante la creación del departamento. Junto con ello, el DAPP estuvo poco preparado para reconocer cuáles eran los objetivos del país en el ámbito internacional, lo que resultaba particularmente grave. El fin último de la diplomacia pública es influir, a través de la opinión pública de cada país, sobre los gobiernos extranjeros, por lo que constituye uno de los engranajes de la política exterior de la nación y debe estar necesariamente alineado con sus objetivos y estrategias.

La propaganda hacia el público interno y la diplomacia pública demostraron ser dos empresas de naturaleza distinta, cuyos requerimientos específicos no podían ser ignorados en nombre de los elementos que tenían en común, como eran el manejo de medios de comunicación y de técnicas persuasivas. Tras tres años de experimentación, el gobierno de Cárdenas pareció comprender que la profesionalización de la propaganda oficial no se alcanzaría a través de la centralización de labores sino que habría de reconocer, necesariamente, tales 
diferencias. Así, tras la supresión del DAPP se optó por volver a separar la propaganda interior de la exterior. La SRE recuperó el control sobre la diplomacia pública no solo gracias a sus presiones burocráticas, sino también por haber demostrado estar mucho mejor compenetrada con dicha misión al comprender la naturaleza de los públicos foráneos y tener claros los objetivos que perseguía el gobierno en sus relaciones internacionales. De esta forma, México tomó distancia del paradigma centralizador utilizado por la propaganda nazi y se orientó en la línea que seguirían las más importantes oficinas de propaganda norteamericanas que se fundaron en las décadas siguientes (como el Office of the Coordinator of Inter-American Affairs de 1940 y la United States Information Agency de 1953), ${ }^{83}$ donde los organismos encargados de hacer propaganda hacia el extranjero funcionaban con total autonomía de las dependencias responsables de la publicidad interna del país, en lo que sería el modelo a seguir a nivel internacional hasta el día de hoy.

\section{Fuentes}

Archivos

Archivo General de la Nación, Fondo Presidentes, Lázaro Cárdenas del Río (AGN P LCR)

Archivo General de la Nación, Fondo Personal Lázaro Cárdenas (AGN FPLC)

Archivo General de la Nación, Fondo Dirección General de Información, serie I (AGN DGI (I))

Archivo General de la Nación, Fondo Dirección General de Información, serie II (AGN DGI (II))

${ }^{83}$ La Office of the Coordinator of Inter-American Affairs (OCIAA), dirigida por Nelson Rockefeller, fue una agencia encargada de fomentar la cooperación de América Latina con Estados Unidos a través de diversos mecanismos de propaganda. En 1945 fue renombrada como Office of Inter-American Affairs (OIAA). La United States Information Agency (USIA), que existió entre 1953 y 1999, fue la agencia norteamericana encargada exclusivamente de la diplomacia pública del país. 
Archivo Histórico Genaro Estrada, Secretaría de Relaciones Exteriores, México (AHGE)

Archivo Histórico Genaro Estrada, Secretaría de Relaciones Exteriores, México /Archivo Personal Francisco Castillo Nájera (AHGE APFCN)

Fondo Agustín Arroyo Ch., Archivo Alhóndiga de Granaditas, Guanajuato (FAACh)

Subsecretaría: Archivo Histórico Secretaría de Educación Pública, Fondo Subsecretaría (SEP)

Alfonso Pulido Isla Papers, Bancroft Library, University of Berkeley (APIP)

Documentos

DAPP (1937), Memoria del Departamento de Prensa y Publicidad, enero a agosto de 1937, México

DAPP (1938), Memoria del Departamento de Prensa y Publicidad, septiembre de 1937 a agosto de 1938, México

Secretaría de Relaciones Exteriores (1941), Memoria de Labores Realizadas Por La Secretaría de Relaciones Exteriores, Septiembre de 1940-Agosto 1941, México

Secretaría de Hacienda y Crédito Público (1940). The True Facts About the Expropiation of the Oil Companies' Properties in Mexico, México.

Secretaría de Economía Nacional, Memoria, septiembre 1939-agosto 1940, México

Decision Rendered by the Supreme Court of Mexico in the Oil Expropiation Case, México (1940)

Bibliografía

BritTon, J. A. (1988). "Propaganda, Property, and the Image of Stability: The Mexican Government and the US Print Media, 1921-1929”. Secolas Annals XIX.

Bussemer, T. (2005). Propaganda: Konzepte Und Theorien. Wiesbaden: VS Verlag 
Chang, K. (2014). "Muted Reception: U. S. Propaganda and the Construction of Mexican Popular Opinion During the Second World War". Diplomatic History 38 (3), p. 569-598.

Creel, G. (1920). How We Advertised Americ. Nueva York: Harper \& Brothers Publishers.

Cronlund Anderson, M. (2000). Pancho Villa’s Revolution by Headlines. Norman: University of Oklahoma Press.

Cruz Porchini, D. (2014). Proyectos Culturales y Visuales En México a Finales Del Cardenismo (1937-1940), tesis de doctorado. México: Universidad Nacional Autónoma de México.

Dоов, L. W. (1950). “Goebbel's Principles of Propaganda”. Public Opinion Quarterly 14 (3), p. 419-442.

Dümmer Scheel, S. (2015). En Defensa de la Revolución: Diplomacia Pública de México hacia Estados Unidos bajo el gobierno de Lázaro Cárdenas (1934-1940), tesis de doctorado. Berlín: Freie Universität Berlin.

Gilly, A. (1994). El Cardenismo: Una Utopía Mexicana. México: Cal y Arena. González Salinas, O. F. (2016). "El discurso patriótico y el aparato propagandístico que sustentaron a la expropiación petrolera durante el cardenismo". Estudios de Historia Moderna y Contemporánea de México 52, p. 88-107.

KaTAN, D. (2014). Translating Cultures: An Introduction for Translators, Interpreters and Mediators. Londres: Routledge.

López González, R. (2002). Departamento Autónomo de Prensa y Propaganda (DAPP). La Experiencia Del Estado Cardenista En Políticas Estatales de Comunicación 1937-1939, tesis de licenciatura. México: Universidad Nacional Autónoma de México.

MacíAs Richard, C. (1991). "Diplomacia y Propaganda Mexicana En Estados Unidos (1920-1924)”. Revista Eslabones 2.

Medin, T. (1975). Ideología y Praxis Política de Lázaro Cárdenas. México: Siglo XXI.

Mejía Barquera, F. (2010). "El Departamento Autónomo de Prensa y Publicidad (1937-1939)”. Fundación Manuel Buendía 3. 
Meyer, L. (1972). México y los Estados Unidos en el conflicto petrolero (19171942). 2a ed. México: El Colegio de México.

Mijares Palencia. (1936). El Gobierno Mexicano, México.

Pilatowsky GoÑi, P. (2014). Para dirigir la acción y unificar el pensamiento. Propaganda y Revolución en México, 1936-1942, tesis de doctorado. México: El Colegio de México.

Rivera P. C., J. (1939). Publicidad turística de México. México: DAPP.

Ruiz OJeda, T. C. (2012). El Departamento Autónomo de Prensa y Publicidad; Construyendo la nación a través del cine documental en México (19371939), tesis de doctorado. México: Universidad Michoacana de San Nicolás de Hidalgo.

SEmo, I. (1993). "El Cardenismo Revisado: La tercera vía y otras utopías inciertas”. Revista Mexicana de Sociología 55 (2), p. 197-223.

Sмiтh, M. M. (1995). "Carrancista Propaganda and the Print Media in the United States: An Overview of Institutions”. The Americas 52 (2), p. 155-174.

Sproule, M. (2005). Propaganda and Democracy: The American Experience of Media and Mass Persuasion. Cambridge: Cambridge University Press.

Strauss Neuman, M. (1983). El reconocimiento de Álvaro Obregón: opinión americana y propaganda mexicana (1921-1923). México: Universidad Nacional Autónoma de México.

VÁZquez Mantecón, Á. (2013). “Cine y propaganda durante el cardenismo”. Historia y Grafía 39, p. 86-101.

Yankelevich, P. (1995). “Las Campañas Pro México”. Cuadernos Americanos 1 (49), p. 79-95.

YANKeleVich, P. (1997). Miradas australes. Propaganda, cabildeo y proyección de la Revolución mexicana en el Río de La Plata, 1910-1930. México: Instituto Nacional de Estudios Históricos de la Revolución Mexicana.

Yankelevich, P. (1999). En la retaguardia de la Revolución mexicana. Propaganda y propagandistas mexicanos en América Latina. 1914-1920. Barcelona: Universitat de Barcelona. 